\title{
Antibody Responses Induced by Japanese Whole Inactivated Vaccines against Equine Influenza Virus (H3N8) Belonging to Florida Sublineage Clade2
}

\author{
Takashi YAMANAKA ${ }^{1) *}$, Hiroshi BANNAI ${ }^{1}$, Manabu NEMOTO ${ }^{1)}$, Koji TSUJIMURA ${ }^{1)}$, Takashi KONDO $^{1)}$ and \\ Tomio MATSUMURA ${ }^{1)}$ \\ ${ }^{1)}$ Epizootic Research Center, Equine Research Institute, Japan Racing Association, 1400-4 Shiba, Shimotsuke, Tochigi 329-0412, Japan
}

(Received 17 September 2010/Accepted 5 November 2010/Published online in J-STAGE 19 November 2010)

ABSTRACT. In 2010, the World Organisation for Animal Health recommended the inclusion of a Florida sublineage clade2 strain of equine influenza virus (H3N8), which is represented by A/equine/Richmond/1/07 (Richmond07), in equine influenza vaccines. Here, we evaluate the antigenic differences between Japanese vaccine strains and Richmond07 by performing hemagglutination inhibition (HI) assays. Ferret antiserum raised to A/equine/La Plata/93 (La Plata93), which is a Japanese vaccine strain, reacted with Richmond07 at a similar titer to La Plata93. Moreover, two hundred racehorses exhibited similar geometric mean HI antibody titers against La Plata93 and Richmond07 (73.1 and 80.8, respectively). Therefore, we can expect the antibody induced by the current Japanese vaccines to provide some protection against Richmond07-like viruses.

KEY WORDS: equine influenza, Florida sublineage, vaccine.

J. Vet. Med. Sci. 73(4): 483-485, 2011

Equine influenza virus is one of the family Orthomyxoviridae, and can lead to an acute respiratory disease in horses [9]. Although viruses with two subtypes, H7N7 and $\mathrm{H} 3 \mathrm{~N} 8$, have been identified, the H7N7 virus has not been isolated from horses since 1979 [21]. It is currently widely accepted that the H7N7 virus may be extinct [19]. On the other hand, the H3N8 virus is still circulating among horses worldwide [5, 19].

Vaccination using whole/subunit inactivated vaccines is widely used as a prophylaxis measure against equine influenza [16]. Whole/subunit inactivated vaccines provide protection by inducing an antibody to the viral surface glycoproteins, in particular, the hemagglutinin [16]. The efficacy of protection induced by an equine influenza vaccine strain against another strain depends on the antigenic differences between them, as found with other influenza A viruses [23]. Therefore, the composition of available equine influenza vaccines is reviewed annually by the World Organisation for Animal Health (OIE) according to the antigenic characteristics of circulating viruses. In 2009, OIE recommended A/equine/South Africa/4/03-like strains as a vaccine strain [14]. A/equine/South Africa/4/03 (South Africa03) was classified as a Florida sublineage Clade (Fc)1 [3, 14], which has diverged from the American lineage since around 1996 [10, 11]. In 2010, OIE recommended the inclusion of an Fc2 strain of equine influenza virus (H3N8), which is represented by A/equine/Richmond/1/07 (Richmond07) [15], in equine influenza vaccines because Fc2 viruses have been widely circulating in the United Kingdom and Eurasia [1, 4, 6, 18, 20], and the antigenic characteristics of Fc1 and clade2 are distinguishable. Fc2

\footnotetext{
* Correspondence to: YamanaKa, T., Epizootic Research Center, Equine Research Institute, Japan Racing Association, 1400-4 Shiba, Shimotsuke, Tochigi 329-0412, Japan.

e-mail: yamanaka@epizoo.equinst.go.jp
}

appears to have diverged from Fc1 since the first introduction of the latter into the United Kingdom in 2003 [12].

All racehorses in Japan are bi-annually vaccinated following a primary vaccination with commercially available whole inactivated equine influenza vaccines. The current Japanese vaccines contain A/equine/Avesta/93 (Avesta93, Eurasian lineage), A/equine/La Plata/93 (La Plata93, American lineage) and A/equine/Ibaraki/1/07 (Ibaraki07). Avesta93 and La Plata93 were introduced into the vaccines in 2004 and 1996, respectively [8, 13]. Ibaraki07 was isolated from a horse during the equine influenza epidemic in Japan in 2007 and classified as Fc1 [3, 22]. Ibaraki07 was introduced into the Japanese vaccines in October 2009. However, they do not contain an OIE-recommended Fc2 virus at present. Therefore, this raises concerns that the current Japanese vaccines are not effective against $\mathrm{Fc} 2$ viruses. Here, we evaluated the antigenic differences between Japanese vaccine strains and Richmond07 by hemagglutination inhibition (HI) assays in order to assess the efficacy of current Japanese vaccines against Fc2 viruses.

HI assays were performed as previously described [7], using infected allantoic fluids as hemagglutinin antigens and 96-well microplates. Briefly, the antisera were treated with trypsin-heat-potassium metaperiodate to remove nonspecific inhibitors as previously described by Beardmore et al. [2]. Then the required final dilution of treated antiserum $(1: 10)$ was prepared with phosphate buffered saline $(\mathrm{pH}$ : 7.4, PBS) and adsorbed with packed chicken erythrocytes. Two-fold dilutions of the antiserum with PBS were prepared; $25 \mu l$ of the diluted serum was used in each well of microplate. To each well, $25 \mu l$ of virus containing 4 hemagglutination units was added, and the microplate was incubated at room temperature for $30 \mathrm{~min}$. Then $50 \mu \mathrm{l}$ of $0.5 \%$ chicken erythrocytes was added to each well. The results were read after incubation at room temperature for 
Table 1. Hemagglutination inhibition titers with ferret antisera

\begin{tabular}{lcccccr}
\hline & & \multicolumn{3}{c}{ Ferret antisera raised to: } \\
Virus $^{\text {a) }}$ & Mock $^{\text {b) }}$ & Avesta93 & La Plata93 & South Africa03 & Ibaraki07 & Richmond07 \\
\hline Avesta93 (Eurasian) & $<10$ & $\underline{320}$ & 10 & 10 & 40 & 80 \\
La Plata93 (American) & $<10$ & $<10$ & $\underline{40}$ & 20 & 10 & 320 \\
South Africa03 (Florida sublineage Clade1) & $<10$ & $<10$ & 40 & $\underline{160}$ & 80 & 80 \\
Ibaraki07 (Florida sublineage Clade1) & $<10$ & 10 & 40 & 40 & $\underline{160}$ & 40 \\
Richmond07 (Florida sublineage Clade2) & $<10$ & $<10$ & 40 & 40 & 10 & $\underline{320}$
\end{tabular}

a) See the text for abbreviations. The virus lineages are given in parentheses. b) Uninfected control.

$60 \mathrm{~min}$. The HI antibody titers were determined by the reciprocal of the highest serum dilution that exhibited no hemagglutination. Viruses were tested against ferret antisera raised to Avesta93, La Plata93, South Africa03, Ibaraki07 and Richmond07. The pooled ferret antiserum was produced by exposing 2-3 ferrets to each virus $\left(10^{7.6}\right.$ $10^{8.3} 50 \%$ egg infectious dose) in a chamber $\left(7 \mathrm{~m}^{3}\right)$ for 20 min using an ultrasonic nebulizer (SONICLIZER305; ATOM, Tokyo, Japan), except for the antiserum against Richmond07 provided by Dr. Debra M. Elton (Animal Health Trust, U.K.) [4].

The HI antibody titers with the ferret antisera are shown in Table 1. The reactivity of ferret antiserum raised to Avesta93 was limited to the homologous virus. The ferret antiserum raised to La Plata93 reacted with all the tested viruses at the same titer, with the exception of Avesta93. The reactivity of ferret antiserum raised to South Africa03 was limited to the homologous virus. The HI antibody titers of ferret antiserum raised to South Africa03 against the heterologous viruses were 4 to 16 times lower than the homologous titer. The HI antibody titer of ferret antiserum raised to Ibaraki07 against South Africa03 was only 2 times lower than the homologous titer. However, the HI antibody titers of antiserum raised to Ibaraki07 against the other heterologous viruses (Avesta93, La Plata93 and Richmond07) were 4 to 16 times lower than the homologous titer. The HI antibody titers of antiserum raised to Richmond07 against the heterologous viruses were 4 to 8 times lower than the homologous titer, with the exception of La Plata93. The antisera raised to Richmond07 reacted with La Plata93 at the same titer as the homologous virus. In accordance with Bryant's report [4], the present data showed that the antiserum raised to South Africa03 or Ibaraki07 classified as Fc1 reacts poorly with Richmond07. Moreover, the antiserum raised to La Plata93 belonging to the American lineage reacted with Richmond07 at the same titer as the homologous virus.

To survey the distribution of $\mathrm{HI}$ antibody titers against Richmond07 among vaccinated racehorses in Japan, we tested two hundred sera collected in May 2010 from threeyear-old Thoroughbred racehorses by performing HI assays using Richmond07 and the Japanese vaccine strains ( $\mathrm{La}$ Plata93, Avesta93 and Ibaraki07) as hemagglutinin antigens. All the horses had received bi-annual booster vaccinations following primary vaccinations at the age of one in
2008. The last vaccination was performed in November 2009.

The geometric mean HI antibody titers of the horses against Richmond07, La Plata93, Avesta93 and Ibaraki07 were 80.8, 73.1, 42.1 and 49.2, respectively. Although the homologous titer of the ferret antiserum raised to La Plata93 was 4 to 8 times lower than those of the other ferret antisera, the geometric mean $\mathrm{HI}$ antibody titer against La Plata93 of horses was higher than those against the other vaccine strains (Avesta93 and Ibaraki07). Powell et al. [17] reported that the clinical morbidity rate of horses with an $\mathrm{HI}$ antibody titer of more than $>40-80$ or $>80$ was 10 or $0 \%$, respectively, during the outbreak in Hong Kong in 1992. From these above, it is suggested that not only the Japanese vaccine strains possess the adequate immunogenicities in horses, but also they can induce an antibody reacting well with Richmond07.

Bryant et al. [4] mentioned that the antibody induced by an American lineage strain may protect against $\mathrm{Fc} 2$ viruses because the two American lineage strains (A/equine/Newmarket/1/93 and A/equine/Kentucky/98) are antigenically similar to the $\mathrm{Fc} 2$ viruses including Richmond07. Also in this study, the ferret antiserum raised to La Plata93 reacted with Richmond07 at the same titer against the homologous virus. Taken together, the geometric mean HI antibody titer of the horses against Richmond07 is probably due to a crossreactivity of antibody induced by La Plata93 belonging to American lineage.

Our data showed that the antibody induced by the Japanese equine influenza vaccines containing La Plata93 reacts well with Richmond07. Therefore, we can expect the antibody induced by the current Japanese equine influenza vaccines to provide some protection against Richmond07-like viruses.

ACKNOWLEDGMENTS. We thank Dr. Debra M. Elton for providing Richmond07 and its specific ferret antiserum. We also thank Dr. Alan Guthrie (University of Pretoria, SA) for providing South Africa03.

\section{REFERENCES}

1. Barbic, L., Madic, J., Turk, N. and Daly, J. 2009. Vaccine failure caused an outbreak of equine influenza in Croatia. Vet. Microbiol. 133: 164-171.

2. Beardmore, W. B., Jones, K. V., Clark, T. D. and Hebeka, E. 
K. 1968. Induction of an inhibitor of influenza virus hemagglutination by treatment of serum with periodate. Appl. Microbiol. 16: $563-568$.

3. Bryant, N. A., Rash, A. S., Russell, C. A., Ross, J., Cooke, A., Bowman, S., MacRae, S., Lewis, N. S., Paillot, R., Zanoni, R., Meier, H., Griffiths, L. A., Daly, J. M., Tiwari, A., Chambers, T. M., Newton, J. R. and Elton, D. M. 2009. Antigenic and genetic variations in European and North American equine influenza virus strains (H3N8) isolated from 2006 to 2007. Vet. Microbiol. 138: 41-52.

4. Bryant, N. A., Rash, A. S., Woodward, A. L., Medcalf, E., Helwegen, M., Wohlfender, F., Cruz, F., Herrmann, C., Borchers, K., Tiwari, A., Chambers, T. M., Newton, J. R., Mumford, J. A. and Elton, D. M. 2010. Isolation and characterisation of equine influenza viruses (H3N8) from Europe and North America from 2008 to 2009. Vet. Microbiol. (in press).

5. Daly, J. M., Macrae, S., Newton, J. R., Wattrang, E. and Elton, D. M. 2010. Equine influenza: a review of an unpredictable virus. Vet. J. (in press).

6. Damiani, A. M., Scicluna, M. T., Ciabatti, I., Cardeti, G., Sala, M., Vulcano, G., Cordioli, P., Martella, V., Amaddeo, D. and Autorino, G. L. 2008. Genetic characterization of equine influenza viruses isolated in Italy between 1999 and 2005. Virus Res. 131: 100-105.

7. Imagawa, H., Fukunaga, Y., Kamada, M., Nanbu, M. and Kitamura, M. 1993. Distribution of HI antibody against 3 vaccine strains of equine influenza in light-breed horses in Japan. $J$. Equine Sci. 4: 31-38.

8. Imagawa, H., Sugita, S., Fukunaga, Y., Kamada, M. and Izuchi, T. 1997. An equine influenza vaccine containing a recent epidemic strain. J. Equine Sci. 8: 1-6.

9. Kawaoka, Y., Haller, O., Hongo, S., Kaverin, N., Klenk, H. D., Lamb, R. A., McCauley, J., Palese, P., Rimstad, E. and Webster, R. G. 2005. Family Orthomyxoviridae. pp. 681-693. In: Virus Taxonomy Eight Report of the International Committee on Taxonomy of Viruses, Elsevier Academic Press, London.

10. Lai, A. C., Chambers, T. M., Holland, R. E. Jr., Morley, P. S., Haines, D. M., Townsend, H. G. and Barrandeguy, M. 2001. Diverged evolution of recent equine-2 influenza (H3N8) viruses in the Western Hemisphere. Arch. Virol. 146: 10631074.

11. Lai, A. C., Rogers, K. M., Glaser, A., Tudor, L. and Chambers, T. 2004. Alternate circulation of recent equine- 2 influenza viruses (H3N8) from two distinct lineages in the United States. Virus Res. 100: 159-164.

12. Newton, J. R., Daly, J. M., Spencer, L. and Mumford, J. A. 2006. Description of the outbreak of equine influenza (H3N8) in the United Kingdom in 2003, during which recently vaccinated horses in Newmarket developed respiratory disease. Vet. Rec. 158: 185-192.

13. Ohta, M., Yamanaka, T., Yoshinari, M. and Matsumura, T. 2007. Antibody responses against american and european lineage strains of equine- 2 influenza virus among racehorses inoculated with the new vaccine. J. Equine Sci. 18: 117-120.

14. OIE. 2009. Expert surveillance panel on equine influenza vaccine composition-conclusions and recommendations. Bull. Off. Int. Epizoot. 2: 42-43.

15. OIE. 2010. expert surveillance panel on equine influenza vaccine composition-conclusions and recommendations. Bull. Off. Int. Epizoot. 2: 44-45.

16. Paillot, R., Hannant, D., Kydd, J. H. and Daly, J. M. 2006. Vaccination against equine influenza: quid novi? Vaccine $\mathbf{2 4}$ : 4047-4061.

17. Powell, D. G., Watkins, K. L., Li, P. H. and Shortridge, K. F. 1995. Outbreak of equine influenza among horses in Hong Kong during 1992. Vet. Rec. 136: 531-536.

18. Qi, T., Guo, W., Huang, W. Q., Li, H. M., Zhao, L. P., Dai, L. L., He, N., Hao, X. F. and Xiang, W. H. 2010. Genetic evolution of equine influenza viruses isolated in China. Arch. Virol. (in press).

19. van Maanen, C. and Cullinane, A. 2002. Equine influenza virus infections: an update. Vet. Q. 24: 79-94.

20. Virmani, N., Bera, B. C., Singh, B. K., Shanmugasundaram, K., Gulati, B. R., Barua, S., Vaid, R. K., Gupta, A. K. and Singh, R. K. 2009. Equine influenza outbreak in India (200809): virus isolation, sero-epidemiology and phylogenetic analysis of HA gene. Vet. Microbiol. 143: 224-237.

21. Webster, R. G. 1993. Are equine 1 influenza viruses still present in horses? Equine Vet. J. 25: 537-538.

22. Yamanaka, T., Niwa, H., Tsujimura, K., Kondo, T. and Matsumura, T. 2008. Epidemic of equine influenza among vaccinated racehorses in Japan in 2007. J. Vet. Med. Sci. 70: 623625.

23. Yates, P. and Mumford, J. A. 2000. Equine influenza vaccine efficacy: the significance of antigenic variation. Vet. Microbiol. 74: 173-177. 